\title{
Diffuse Blastoid B-Cell Lymphoma
}

National Cancer Institute

\section{Source}

National Cancer Institute. Diffuse Blastoid B-Cell Lymphoma. NCI Thesaurus. Code C37209.

A distinct subtype of high-grade follicular center cell lymphoma, representing a diffuse transformation of conventional follicular lymphoma. Although this type of lymphoma strongly expresses BCL-2, it does not carry the characteristic $t(14 ; 18)(q 32 ; q 21)$ chromosomal translocation found in follicular lymphomas. Instead, extra copies of chromosome 18 are often detected. 